\title{
Interrelationship between Diabetes and Periodontitis: A Review
}

\author{
Pradhan S', Goel K' \\ 'Department of Dental Surgery, National Academy of Medical Sciences, Bir Hospital, Kathmandu, Nepal
}

\section{ABSTRACT}

Evidence for the link between periodontal disease and several systemic diseases is growing rapidly. Diabetes mellitus is a systemic disease with several major complications affecting both the quality and length of life causing morbidity and mortality. Periodontitis, one of these complications, is a chronic infection associated with substantial morbidity in the form of tooth loss and that affects the quality of life directly. The association between diabetes and inflammatory periodontal disease has been studied extensively. The relationship between these two conditions appears bidirectional. The presence of one condition tends to promote the other and the meticulous management of either may assist treatment of the other. It also provides a perfect example of a cyclical association, whereby a systemic disease predisposes the individual to oral infections, and once the oral infection is established, it exacerbates the systemic disease. This review focuses to explain the interrelationship between the two based on information in the literature and the potential common immunoregulatory connections involved, exploring the mechanisms through which periodontal infection can contribute to the low-grade general inflammation associated with diabetes.

Keywords: Diabetes mellitus, inflammation, insulin resistance, periodontitis

\section{INTRODUCTION}

Diabetes mellitus (DM) and periodontitis (PD) are commonly encountered chronic diseases. Diabetes mellitus is a disease of metabolic dysregulation characterized by hyperglycemia due to defects in insulin secretion, insulin action or both. Dysregulation of protein and lipid metabolism also occurs. ${ }^{1}$ Over the past 30 years, DM has been recognized as a major disease associated with high morbidity and mortality. ${ }^{2}$ In Nepal, almost $15 \%$ of people 20 years and above and $20 \%$ of people 40 years and above have been reported to have diabetes in a study in the urban parts of the country. The same study showed that about one third of people above 40 years have glucose intolerance of some form in urban Nepal. ${ }^{3}$
Periodontitis is defined as infections of the tissues surrounding the teeth. This infection is usually caused by anaerobic gram-negative microorganisms. Infection causes destruction of supporting alveolar bone and can lead to tooth loss. ${ }^{4}$ Historically, oral infections were thought to be localized to the oral cavity except in the case of some associated syndromes and untreated odontogenic abcesses. A change in paradigm has dispelled this notion, and a whole new concept of the status of the oral cavity and its impact on systemic health and disease has evolved. Researchers have established a strong relationship between periodontal disease and type 1 and type 2 DM but with conflicting conclusions. Both of the diseases have a relatively high global incidence and some common pathways (polygenic disorders with some degree of immunoregulatory dysfunction) in their pathogenesis. This relationship

\author{
Correspondence: \\ Dr. Shaili Pradhan \\ Department of Dental Surgery \\ National Academy of Medical Sciences, Bir Hospital \\ Kathmandu,Nepal \\ Tel No:977-1-4221988 \\ Email: shaili_p@yahoo.com
}


can be seen clinically and more recently on a molecular level as well. Periodontal disease has been described as the sixth common complication of DM. In order to understand the cellular/molecular mechanism responsible for such a cyclical association, one must identify the common physiological changes associated with diabetes and PD that produce a synergy when conditions coexist. ${ }^{5}$

\section{Diabetes Mellitus Epidemiology}

The prevalence of DM for all age-groups worldwide was estimated to be $2.8 \%$ in and 2000 projected to be $4.4 \%$ in 2030 . It is projected that the total number of people with DM will rise from 171 million in 2000 to 366 million in 2030. Similarly, the urban population in developing countries is projected to double between 2000 and $2030 .^{2}$ In a study of 740 adults (286 men and 454 women) aged 21 to 94 years from the semiurban population of Nepal, the prevalence of Type 2 DM and impaired fasting glucose was $9.5 \%$ and $19.2 \%$. Furthermore, the overall prevalence of Type 2 DM and impaired fasting glucose was found to increase with age. The prevalence of impaired fasting glucose is highest among middle age men whereas the prevalence of Type $2 \mathrm{DM}$ is highest among older men. ${ }^{6}$ The number of people with DM is increasing due to the population growth, aging, urbanization, and increasing prevalence of obesity and physical inactivity. In association with the increasing diabetes prevalence, this will inevitably result in an increasing proportion of deaths from cardiovascular disease as well as an increased prevalence and associated consequences of other complications of diabetes. A concerted, global initiative is required to address the diabetes epidemic. ${ }^{2}$

\section{Classification}

The current classification of DM is based upon the pathophysiology of each form of the disease. ${ }^{7}$ Type 1 diabetes results from cellular-mediated autoimmune destruction of pancreatic $\beta$-cells, usually leading to total loss of insulin secretion. Markers of autoimmune destruction have been identified and can be used for diagnosis or risk assessment. Although type 1 diabetes is usually present in children and adolescents, some studies demonstrated that it forms $15 \%$ to $30 \%$ of all cases of DM being diagnosed after 30 years of age. ${ }^{8}$ In older type 1 patients, the $\beta$-cell destruction occurs more slowly than in children, with a less abrupt onset of symptoms. This demonstrates that the pace and extent of cellular destruction can occur at a different rate from patient to patient. The lack of insulin production in patients with type 1 diabetes makes the use of exogenous insulin necessary to sustain life, hence the former name "insulin-dependent diabetes." In the absence of insulin, these patients develop ketoacidosis, a life-threatening condition. ${ }^{7}$

Type 2 DM, previously called non-insulindependent diabetes, results from insulin resistance, which alters the use of endogenously-produced insulin at the target cells. ${ }^{7}$ Type 2 DM patients can be undiagnosed for many years because the hyperglycemia appears gradually is and often asymptomatic. In many patients, especially early in the disease process, pancreatic insulin production is actually increased to compensate for insulin resistance. As the condition progresses, pancreatic insulin production may diminish over time due to the prolonged increase in secretory demand caused by the insulin resistance. Insulin secretion becomes insufficient to compensate for insulin resistance. The onset of symptoms in type $2 \mathrm{DM}$ is more gradual and less severe, usually presenting after the age of 40 years. ${ }^{9}$

\section{Influence of diabetes on periodontal tissues}

Till date, the influence of diabetes on oral health has been extensively studied. More than 200 articles on the relationship between DM and periodontal diseases have been published in the English literature during the past 50 years. ${ }^{10}$

\section{Gingivitis}

An overall assessment of the available data strongly suggests that diabetes is a risk factor for gingivitis and PD. In a classic study of diabetes and gingivitis reported more than 30 years ago, the prevalence of gingival inflammation was greater in children with type $1 \mathrm{DM}$ than in children without diabetes who had similar plaque levels. ${ }^{11} \mathrm{~A}$ recent longitudinal study showed a more rapid and severe gingival inflammation in adult subjects with type 1 diabetes than in control subjects without diabetes, despite similar qualitative and quantitative bacterial plaque characteristics, suggesting a hyperinflammatory gingival response in people with diabetes. ${ }^{12}$ The onset of type 1 DM in children has been associated with increased gingival bleeding, while improved control of blood sugar levels after initiation of insulin therapy resulted in decreased gingivitis. ${ }^{13}$

\section{Periodontitis}

Epidemiologic studies in diabetic adults have often shown an increase in the extent and severity of PD. A 
large number of the studies on periodontal disease in patients with type 2 DM have been conducted on the Pima Indians from the Gila River Indian Community in Arizona. With 50 percent of its population older than 35 years of age having type 2 diabetes, it is the a population with the highest occurrence of type 2 DM in the world. In a study of this population in 15 years of age or older, the incidence and prevalence of periodontal disease were determined in 2,273 subjects. Following these subjects for an average of over 2.5 years, the incidence of PD was 2.6 fold higher in diabetic subjects than in non-diabetic patients. ${ }^{14,}{ }^{15}$ In a meta analysis including more than 3,500 adults with diabetes, a significant association between diabetes and PD was demonstrated. ${ }^{16}$ Like gingivitis, the risk of developing PD may be greater in patients with diabetes who have poor glycemic control than that in patients with wellcontrolled diabetes. There is significant heterogeneity in the diabetic population. Poor control of diabetes clearly increases the risk of diabetic complications, but there are many poorly-controlled diabetic individuals without major complications. ${ }^{16,} 17$ In a large epidemiologic study in the United States, adults with poorly-controlled diabetes had a 2.9 fold increased risk of having $P D$ compared to non-diabetic adult subjects. Conversely, well-controlled diabetic subjects had no significant increase in the risk of PD. ${ }^{17}$ In a longitudinal Pima Indian studies, poor glycemic control of type 2 diabetes was associated with an 11 fold increased risk of progressive bone loss compared to non-diabetic controls, whereas well-controlled diabetic subjects had no significant increase in risk. ${ }^{18}$ However, other studies have shown only a marginal or insignificant relationship between glycemic control and periodontal status. ${ }^{19-22}$

\section{Mechanism by which diabetes may influence periodontium}

A large evidence base is available to describe the potential mechanisms of diabetes on periodontium, many of which are strikingly similar to those associated with the classic diabetic complications including retinopathy, nephropathy, neuropathy, macrovascular diseases and altered wound healing. The strength of the evidence has led some to suggest that PD should be listed among the "classic" complications of diabetes. ${ }^{5}$

Role of bacterial infection in diabetic patients with periodontitis

Bacteria are the major etiologic factor for PD. However, no significant differences in the microbial flora have been noted between diabetic and non-diabetic subjects although some studies have reported higher levels of
Capnocytophaga species in diabetic patients. ${ }^{23}$ Most culture studies showed that the bacterial microflora at periodontally diseased sites in diabetic subjects is similar to the microflora at similarly diseased sites in nondiabetic subjects. ${ }^{22,24}$ However, the apparent lack of significant differences in potential pathogens suggests that the alterations in the host immunoinflammatory response may have a major influence on the increased prevalence and severity of periodontal destruction seen in diabetes.

\section{Diabetes-induced systemic inflammatory state}

The functions of inflammatory cells, such as neutrophils, monocytes, and macrophages, are altered in diabetic patients. ${ }^{23}$ The impairment in neutrophil function may disturb host defense activity, thereby leading to periodontal destruction. Chemotaxis, adherence, and phagocytosis of neutrophils are impaired, which may inhibit bacterial killing in the periodontal pocket and significantly increase periodontal destruction. ${ }^{25}$, 26 The pentose phosphate pathway is instrumental in the formation of NADPH and ribose-5-phosphate for fatty acid and nucleotide synthesis, respectively. ${ }^{27}$ NADPH is important for NADPH oxidase activity and for the rejuvenation of glutathione in neutrophils; ${ }^{28}$ and activation of NADPH oxidase results in a respiratory burst in neutrophils during the process of phagocytosis. ${ }^{29}$ In diabetic patients, NADPH production is decreased, which leads eventually to compromised neutrophil function. Several studies have indicated that the circulating monocytes from diabetic patients exhibit an exaggerated inflammatory response to gram-negative bacterial lipopolysaccharides, releasing large amounts of inflammatory mediators and proinflammatory cytokine such as IL-1 $\beta$ and TNF- $\alpha .{ }^{30}$ This hyper responsive monocytic phenotype is not associated with hyperglycemia and can exist independently of PD and may be related to hyperlipidemia. ${ }^{31,32,33}$ Studies concerning relationship of diabetes and mononuclear cell cytokine production demonstrated that PMN from diabetic patients exhibits a significant production of IL-1 $\beta$. Thus, effects of diabetes on PMN appear to be similar to blood monocytes relative to hyperinflammatory response and potential predisposition to tissue breakdown. ${ }^{34}$ Because gingival crevicular fluid is a serum transudate, elevated serum levels of inflammatory mediators associated with diabetes are reflected in similarly-increased levels of these mediators in gingival crevicular fluid. ${ }^{35}$ The level of inflammatory cytokines in the gingival crevicular fluid is also related to glycemic control of diabetes. In a study of diabetic subjects with PD, those with $\mathrm{HbA} 1 \mathrm{c}$ levels over $8 \%$ had crevicular fluid levels of interleukin-1 beta (IL-1 $\beta$ ) almost twice as high as subjects with $\mathrm{HbA1c}$ 
levels of $<8 \%$. $^{36}$ The net effect of these host defense alterations in diabetes is an increase in periodontal inflammation, attachment loss and bone loss.

Altered wound healing is one of the most common complications of DM. High glucose levels in the gingival crevicular fluid may directly hinder the wound-healing capacity of fibroblasts in the periodontium by inhibiting attachment and spreading of these cells that are critical to wound healing and normal tissue turnover. ${ }^{37}$ Also, production of essential growth factors such as platelet derived growth factor, transforming growth factorbeta, and fibroblastic growth factor is significantly reduced. ${ }^{38,39}$ Reduced growth factor production at local tissue sites may diminish the repair capacity and the ability of tissues to resist proinflammatory cytokinemediated breakdown. ${ }^{40}$

The increased levels of periodontal attachment and bone loss seen in diabetic patients may be associated with the alterations in connective tissue metabolism that uncouple the resorptive and formative responses. Impaired osseous healing and bone turnover in association with hyperglycemia have been demonstrated in a number of studies. Diabetes may cause a net loss of bone because the suppression of bone formation is greater than the suppression of bone resorption. The uncoupling of bone formation and resorption may be due in part to prolonged apoptosis of bone lining cells. There is not only inhibition of osteoclastogenesis and resorption in diabetic animals but also the reduction of new bone formation to an even greater extent. ${ }^{41}$ Microvascular changes are a hallmark of many diabetic complications. ${ }^{42}$ The changes seen in the microvasculature of the retina, glomerulus, and other end organs in people with diabetic complications also occur in the periodontium. ${ }^{43,44}$ In individuals with sustained hyperglycemia, proteins become irreversibly glycated to form advanced glycation end products (AGEs). ${ }^{45}$ These stable carbohydrate-containing proteins have multiple effects on cell-to-cell and cell-to-matrix interactions and are commonly thought to be a major link between the various diabetic complications. The formation of AGEs also occurs in the periodontium, and higher levels of periodontal AGE accumulation are found in those with diabetes than in non-diabetic subjects. ${ }^{46}$ AGEs often form on collagen, increasing collagen cross-linking and resulting in the formation of highly stable collagen macromolecules. These molecules accumulate in tissues due to their resistance to normal enzymatic degradation and tissue turnover. ${ }^{45}$ The basement membranes of endothelial cells also accumulate AGE-modified collagen macromolecules that can result in increased basement membrane thickness in the microvasculature, altering normal homeostatic transport across the membrane, ${ }^{47}$ hyperglycemic environment can impair oxygen diffusion, metabolic waste elimination, PMN migration, and diffusion of antibodies. This increased basement membrane thickness is seen in the blood vessels of the periodontium in people with diabetes. ${ }^{43}$ AGEs activate a receptor known as "receptor for AGEs" (RAGE) found on the surface of smooth muscle cells, endothelial cells, neurons, and monocytes/macrophages. ${ }^{48}$ This receptor is found in the periodontium, and a $50 \%$ increase in mRNA for RAGE was identified in the gingival tissues of type 2 diabetic subjects compared to non-diabetic controls. ${ }^{46,49}$ The AGE-RAGE interaction on monocytes increases cellular oxidant stress and activates the transcription factor nuclear factor kappa $\beta$ (NF-k $\beta$ ), which alters the phenotype of the monocyte/macrophage and results in the increased production of proinflammatory cytokines such as IL- $1 \beta$ and TNF- $\alpha .{ }^{48}$ This increased production of proinflammatory cytokines is critical to the chronic inflammatory process in the formation of atheromatous lesions in the larger blood vessels. ${ }^{50}$ Increased oxidant stress has also been demonstrated in the gingiva of diabetic subjects in association with an increased accumulation of AGEs. It is this interaction between the receptor RAGE and AGEs in periodontal tissues that is thought to explain, in part, the marked elevation in gingival crevicular fluid levels of IL-1 $\beta$, TNF- $\alpha$, and prostaglandin E2 (PGE2) seen in diabetic subjects compared to non-diabetic individuals. ${ }^{36}$

Collagen is the major structural protein in the periodontium. Human gingival fibroblasts produce decreased amounts of collagen and glycosaminoglycans in high-glucose environments. ${ }^{51}$ In addition to decreased synthesis, newly formed collagen is susceptible to degradation by matrix metalloproteinases such as collagenase, which are elevated in diabetic tissues, including the periodontium. ${ }^{52,53}$ Additionally, studies have demonstrated that TGF- $\beta 1$ activates matrix metalloproteinase-2 (gelatinase A). Gelatinase A plays a pivotal role to dampen inflammation and tissue destruction as it cleaves and inactivates monocyte chemoattractant protein-3. ${ }^{54}$

\section{Effect of periodontal disease on diabetic state}

Evidence has consistently indicated that diabetes is a risk factor for increased severity of gingivitis and PD. Conversely, PD may be a risk factor for worsening glycemic control among patients with diabetes and may increase the risk of diabetic complications. A twoyear longitudinal trial demonstrated a sixfold increased risk of worsening glycemic control in patients with type 2 diabetes who had severe PD compared with that in 
subjects with type 2 diabetes who did not have PD. ${ }^{55}$ Cardiovascular diseases are widely prevalent in people with diabetes. A recent longitudinal trial examined the effect of periodontal disease on overall mortality and cardiovascular disease-related mortality in more than 600 subjects with type 2 diabetes. In subjects with severe PD, the death rate from ischemic heart disease was 2.3 times higher than in subjects with no PD or mild PD, and the mortality rate from diabetic nephropathy was 8.5 times higher in the severe PD group after accounting for other known risk factors. The overall mortality rate from cardio-renal disease was 3.5 times higher in subjects with severe PD. ${ }^{56}$ There is conclusive evidence of the importance of glycemic control in the prevention of diabetic complications. Results from the landmark Diabetes Control and Complications Trial (type 1 diabetes) and the UK Prospective Diabetes Study (UKPDS) (type 2 diabetes) demonstrated that attaining and maintaining good glycemic control could reduce the risk for and slow the progression of microvascular complications in patients with type 1 and type 2 diabetes.

Intervention trials during the past 15 years have resulted in varied metabolic responses in patients with diabetes. These trials often examined the effects of scaling and root planing on glycemic control, either alone or in combination with adjunctive systemic tetracycline therapy. The first such study, a case series published in 1960, showed that type 1 diabetic patients with PD had a reduction in required insulin doses following scaling and root planing, localized gingivectomy, and selected tooth extraction combined with systemic procaine penicillin G and streptomycin. Some studies have shown that the combination of scaling and root planing with systemic doxycycline therapy is associated with an improvement in periodontal status that is accompanied by significant improvement in glycemic control, as measured by the glycated hemoglobin assay (HbA1c). ${ }^{57}$ The HbA1c test provides an estimate of glycemic control over a period of approximately two to three months before the test, and the normal value is less than 6 percent. ${ }^{58}$ Conversely, a recent study of subjects with type 2 diabetes who underwent scaling and root planing and received adjunctive doxycycline therapy demonstrated significant improvement in periodontal health but only a nonsignificant reduction in $\mathrm{HbA} 1 \mathrm{c}$ values. ${ }^{59}$ When researchers performed scaling and root planing but did not administer adjunctive antibiotic therapy, the study results were similarly equivocal. Some studies showed significant improvement in glycemic control after treatment, ${ }^{60,61}$ while others showed no significant improvement in glycemic control despite improvements in patients' periodontal health. ${ }^{62,63} \mathrm{~A}$ recent meta-analysis of 10 intervention trials included 456 patients. After periodontal therapy, the weighted average decrease in absolute $\mathrm{HbA} 1 \mathrm{c}$ values was $0.4 \%$, but this was not found to be statistically significant. ${ }^{64}$ The addition of adjunctive systemic antibiotics to the mechanical therapy regimen resulted in an average absolute reduction of $0.7 \%$. Again, this reduction did not achieve a level of statistical significance. The authors of this meta analysis pointed out numerous problems with existing studies including inadequate sample sizes, mixing of subjects with type 1 and type 2 diabetes, and confounding effects of smoking, body mass index, and medications, among others. Further studies are required to determine whether periodontal therapy provides a significant benefit on glycemic control.

\section{Possible pathological mechanism linking periodontitis and diabetes}

The concept that oral conditions can significantly influence events elsewhere in the body is not new. The probable link between oral and systemic disease dates back to 1900 when the concept of 'Oral sepsis' was put forward by a British physician, William Hunter. 65 The concept of focal infection ("focal infection theory" suggesting that "microorganisms or their waste products obtain entrance of parts of the body adjacent to or remote from the mouth". ${ }^{66}$ ) has been linked to conditions of periodontal diseases as far back as 1912 by Frank Billings. Periodontal disease is initiated by bacteria, and in instances of severe periodontal disease, these bacteria can enter the blood stream and produce an "asymptomatic bacteremia". This has most recently been demonstrated in study where periodontal pathogens were found within coronary vasculature as a result of transient bacteremias. ${ }^{67,68}$ Studies suggest that PD patients, particularly those colonized by Gram-negative organisms such as $P$. gingivalis, Tannerella forsythensis, and Prevotella intermedia, have significantly higher serum markers of inflammation such as C-reactive protein(CRP), IL-6, and fibrinogen than subjects without PD. ${ }^{68}$ Periodontal treatment not only reduces clinically evident inflammation, but may also result in decreased serum levels of IL-6 and CRP. ${ }^{69}$ This evidence suggests that periodontal diseases have systemic effects that extend beyond the local periodontal environment. Because of the predominance of Gram-negative anaerobic bacteria in periodontal infection, the ulcerated pocket epithelium is thought to constitute a chronic source of systemic challenge from bacteria, bacterial products and locally produced inflammatory mediators. ${ }^{70}$ All mediators like TNF- $\alpha$, IL- 6 and IL-I $\beta$ are important in periodontal inflammation and elevations of these cytokines in PD 
may be mediated by "systemic dumping" of locally produced IL-1 $\beta /$ TNF- $\alpha^{71,72}$ and low level "asymptomatic bacteremia/endotoxemia". ${ }^{67,73}$ There has been recent documentation of PD-induced elevations of serum proinflammatory cytokines. ${ }^{74}$ Also because of the high vascularity of the inflamed periodontium, this inflamed tissue may serve as an endocrine-like source for TNF- $\alpha$ and other inflammatory mediators. These mediators have also been shown to have effects on glucose and lipid metabolism, particularly following an acute infectious challenge or trauma. TNF- $\alpha$ has been reported to interfere with lipid metabolism and to be an insulin antagonist, ${ }^{75}$ and IL- 6 and IL-I $\beta$ have been reported to antagonize insulin action. ${ }^{76}$ This would be especially problematic in diabetic patients who already exhibit a systemic monocytic hyperresponsive trait. ${ }^{31}$ The potential impact of elevated systemic proinflammatory mediators in subjects with diabetes is tremendous. Furthermore, obesity is associated with high plasma levels of TNF- $\alpha$ and its soluble receptors, which in turn may lead to a hyperinflammatory state increasing the risk for periodontal disease and also accounting in part for insulin resistance. Although the exact physiologic pathways have not been fully delineated, the increased insulin resistance is caused by elevated production of TNF- $\alpha$ and IL- 6 and decreased production of adiponectin. ${ }^{77}$ Systemic inflammation is significantly elevated in the presence of obesity, insulin resistance, hyperglycemia, and diabetes.

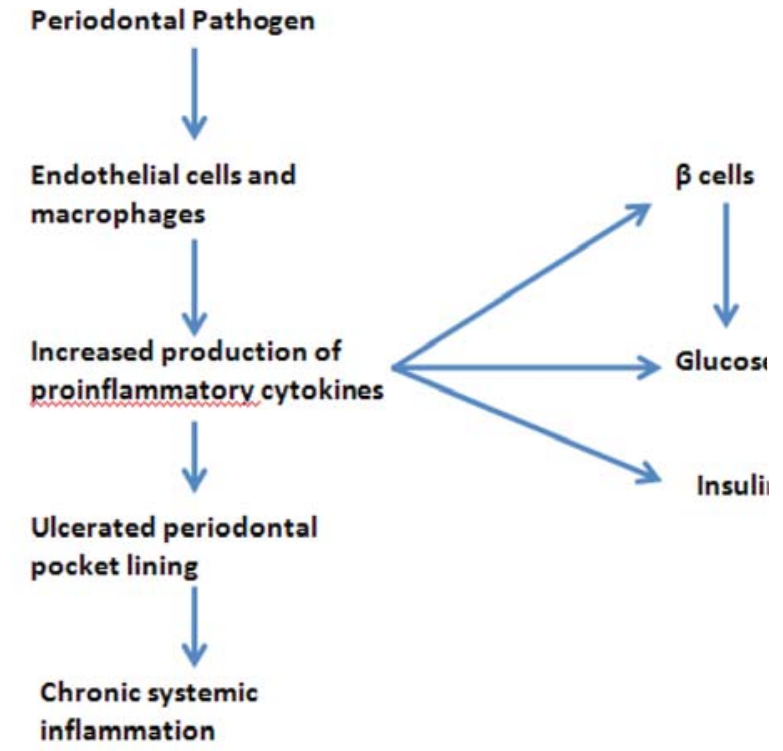

Figure 1. Model for periodontal infection contributing to systemic inflammation and complicating DM. ${ }^{78}$

\section{Infection and insulin resistance}

Although the pathogenesis is poorly understood, it is generally accepted that the infections results in a state of insulin resistance and that bacterial LPS has significant effect on insulin sensitivity. ${ }^{79}$ It has been demonstrated that IL-1 $\beta$ facilitates protein kinase $C$ activation leading to pancreatic $\beta$-cell destruction through apoptotic mechanism. ${ }^{80}$ Tumour necrosis factor- $\alpha$ (TNF- $\alpha)$ has been implicated as a causative factor in insulin resistance and type 2 diabetes in animal models and human studies. ${ }^{81}$ Elevated levels of TNF- $\alpha$ alter intracellular insulin signaling (inhibiting tyrosine kinase activity of insulin receptor) and reduce the synthesis of insulin responsive glucose transporter, creating an insulin resistance syndrome similar to insulin resistance that characterizes type 2 diabetes. ${ }^{82}$ Additionally, TNF- $\alpha$ has been implicated in development of macrophage dependent cytotoxicity of pancreatic islets in diabetes. ${ }^{81}$

\section{Periodontitis and insulin resistance}

Studies have shown that the PD may initiate or propagate insulin resistance by enhancing activation of the overall systemic immune response initiated by cytokines. ${ }^{83,84}$ Given these mechanisms promoting insulin resistance, it seems that in individuals with type 2 diabetes and $\mathrm{PD}$, an elevated chronic systemic inflammatory state induced by periodontal disease may contribute to insulin resistance through a "feed-forward" mechanism that worsens glycemic control. ${ }^{84}$ This might explain why PD increases the risk of poor glycemic control among patients with type 2 diabetes. PD may also contribute to the elevation of serum inflammatory mediators through enhanced in-vitro production of TNF- $\alpha$, Interleukin $-\beta$ and prostaglandin E2 by monocytes, as has been shown in patients, with both diabetes and PD. Furthermore, there was a dose-response relationship between the severity of PD and serum TNF- $\alpha$ level, which suggested that periodontal disease may play a major role in elevating levels of this cytokine, which is closely linked to insulin resistance. ${ }^{85}$ In order to determine whether PD induces insulin resistance, future studies will need to evaluate this in a very precise and consistent manner.

In a manner similar to other bacterial infections, the relationship between DM and periodontal infection becomes two way. This dual mechanism of tissue destruction suggests that control of periodontal infection is essential to achieve long term control of $\mathrm{DM}^{70}$. 


\section{Effects of diabetes on the response to periodontal therapy}

Only limited evidence is available to evaluate the comparative response to periodontal therapy in diabetic and non-diabetic patients with PD. In well-controlled diabetic subjects, the clinical and microbiologic response to scaling and root planing appears similar to that in non-diabetic individuals. ${ }^{63,86}$ In one longitudinal study, 20 diabetic and 20 non-diabetic subjects received scaling and root planing, modified Widman flap surgery at sites with residual probing depths $\geq 5 \mathrm{~mm}$, and regular maintenance therapy. Five years after the baseline examination, diabetic and nondiabetic subjects had similar results in clinical attachment. The HbA1c values revealed that most of the diabetic subjects in this study were well controlled or moderately controlled at baseline. ${ }^{87}$

\section{CONCLUSIONS}

Evidence is emerging to suggest that periodontal disease is associated with increased risk for diabetes complications. Because periodontal diseases are "silent" in nature, most patients do not realize that they have such conditions until significant destruction has occurred. It is important for clinicians to discuss with their diabetic patients the increased risk for periodontal diseases. Treating periodontal infection in people with diabetes is clearly an important component in maintaining oral health. It may also have an important role in establishing and maintaining glycemic control and possibly in delaying the onset or progression of diabetic complications. Clinical trials and systematic studies in diverse population are warranted to support existing evidence that treating periodontal infections can contribute to glycemic control management and possibly to the reduction of the burden of complications of DM.

\section{REFERENCES}

1. Taylor GW. Bidirectional interrelationships between diabetes and periodontal diseases: an epidemiologic perspective. Ann Periodontol. 2001 Dec;6(1):99-112.

2. Wild S, Roglic G, Green A, Sicree R, King H. Global prevalence of diabetes: estimates for the year 2000 and projections for 2030. Diabetes Care. 2004 May;27(5):1047-53.

3. Singh DL, Bhattarai MD. High prevalence of diabetes and impaired fasting glycaemia in urban Nepal. Diabet Med. 2003 Feb;20(2):170-1

4. Pucher J, Stewart J. Periodontal disease and diabetes mellitus. Curr Diab Rep. 2004 Feb;4(1):46-50.

5. Loe H. Periodontal disease. The sixth complication of diabetes mellitus. Diabetes Care. 1993 Jan;16(1):329-34.

6. Ono K, Limbu YR, Rai SK, Kurokawa M, Yanagida J, Rai G, et al. The prevalence of type 2 diabetes mellitus and impaired fasting glucose in semi-urban population of Nepal. Nepal Med Coll J. 2007 Sep;9(3):154-6.

7. American Diabetes Association Diagnosis and classification of diabetes mellitus. Diabetes Care. 2005 Jan;28 Suppl 1:S3742 .

8. DeFronzo RA, Ferrannini E. Insulin resistance. A multifaceted syndrome responsible for NIDDM, obesity, hypertension, dyslipidemia, and atherosclerotic cardiovascular disease. Diabetes Care. 1991 Mar;14(3):173-94.

9. Rhodes CJ. Type 2 diabetes-a matter of beta-cell life and death? Science. 2005 Jan 21;307(5708):380-4.

10. Mealey BL. Periodontal disease and diabetes. A two-way street. J Am Dent Assoc. 2006 Oct;137 Suppl:26S-31S.
11. Cianciola LJ, Park BH, Bruck E, Mosovich L, Genco RJ. Prevalence of periodontal disease in insulin-dependent diabetes mellitus (juvenile diabetes). J Am Dent Assoc. 1982 May;104(5):653-60.

12. Salvi GE, Kandylaki M, Troendle A, Persson GR, Lang NP. Experimental gingivitis in type 1 diabetics: a controlled clinical and microbiological study. J Clin Periodontol. 2005 Mar;32(3):310-6

13. Karjalainen KM, Knuuttila ML. The onset of diabetes and poor metabolic control increases gingival bleeding in children and adolescents with insulin-dependent diabetes mellitus. J Clin Periodontol. 1996 Dec;23(12):1060-7.

14. Emrich LJ, Shlossman M, Genco RJ. Periodontal disease in non-insulin-dependent diabetes mellitus. J Periodontol. 1991 Feb;62(2):123-31.

15. Shlossman M, Knowler WC, Pettitt DJ, Genco RJ. Type 2 diabetes mellitus and periodontal disease. J Am Dent Assoc. 1990 Oct;121(4):532-6.

16. Papapanou PN. Periodontal diseases: epidemiology. Ann Periodontol. 1996 Nov;1(1):1-36.

17. Tsai C, Hayes C, Taylor GW. Glycemic control of type 2 diabetes and severe periodontal disease in the US adult population. Community Dent Oral Epidemiol. 2002 Jun;30(3):182-92.

18. Taylor GW, Burt BA, Becker MP, Genco RJ, Shlossman M, Knowler WC, et al. Non-insulin dependent diabetes mellitus and alveolar bone loss progression over 2 years. J Periodontol. 1998 Jan;69(1):76-83.

19. Bridges RB, Anderson JW, Saxe SR, Gregory K, Bridges SR. Periodontal status of diabetic and non-diabetic men: effects of smoking, glycemic control, and socioeconomic factors. J Periodontol. 1996 Nov;67(11):1185-92. 
20. Tervonen $\mathrm{T}$, Karjalainen $\mathrm{K}$, Knuuttila M, Huumonen S. Alveolar bone loss in type 1 diabetic subjects. J Clin Periodontol. 2000 Aug;27(8):567-71.

21. FA B. Chronic focal infections and their etiologic relations to arthritis and nephritis. Arch Intern Med. 1912;9:484-98.

22. Sastrowijoto SH, Hillemans $\mathrm{P}$, van Steenbergen TJ, Abraham-Inpijn L, deGraaff J. Periodontal condition and microbiology of healthy and diseased periodontal pockets in type 1 diabetes mellitus patients. J Clin Periodontol. 1989 May;16(5):316-22.

23. Mealey B. Diabetes and periodontal diseases. J Periodontol. 1999 Aug;70(8):935-49.

24. Zambon JJ, Reynolds H, Fisher JG, Shlossman M, Dunford R, Genco RJ. Microbiological and immunological studies of adult periodontitis in patients with noninsulin-dependent diabetes mellitus. J Periodontol. 1988 Jan;59(1):23-31.

25. Manouchehr-Pour M, Spagnuolo PJ, Rodman HM, Bissada NF. Comparison of neutrophil chemotactic response in diabetic patients with mild and severe periodontal disease. J Periodontol. 1981 Aug;52(8):410-5.

26. McMullen JA, Van Dyke TE, Horoszewicz HU, Genco RJ. Neutrophil chemotaxis in individuals with advanced periodontal disease and a genetic predisposition to diabetes mellitus. J Periodontol. 1981 Apr;52(4):167-73.

27. Casazza JP, Veech RL. The measurement of xylulose 5-phosphate, ribulose 5-phosphate, and combined sedoheptulose 7-phosphate and ribose 5-phosphate in liver tissue. Anal Biochem. 1986 Dec;159(2):243-8.

28. Curi TC, DeMelo MP, Palanch AC, Miyasaka CK, Curi R. Percentage of phagocytosis, production of $\mathrm{O} 2 .-, \mathrm{H} 2 \mathrm{O} 2$ and $\mathrm{NO}$, and antioxidant enzyme activities of rat neutrophils in culture. Cell Biochem Funct. 1998 Mar;16(1):43-9.

29. Bellavite P. The superoxide-forming enzymatic system of phagocytes. Free Radic Biol Med. 1988;4(4):225-61.

30. Pociot F, Briant L, Jongeneel CV, Molvig J, Worsaae H, Abbal $\mathrm{M}$, et al. Association of tumor necrosis factor (TNF) and class II major histocompatibility complex alleles with the secretion of TNF-alpha and TNF-beta by human mononuclear cells: a possible link to insulin-dependent diabetes mellitus. Eur J Immunol. 1993 Jan;23(1):224-31.

31. Salvi GE, Collins JG, Yalda B, Arnold RR, Lang NP, Offenbacher S. Monocytic TNF alpha secretion patterns in IDDM patients with periodontal diseases. J Clin Periodontol. 1997 Jan;24(1):8-16.

32. Salvi GE, Beck JD, Offenbacher S. PGE2, IL-1 beta, and TNFalpha responses in diabetics as modifiers of periodontal disease expression. Ann Periodontol. 1998 Jul;3(1):40-50.

33. Thomas CE, Jackson RL, Ohlweiler DF, Ku G. Multiple lipid oxidation products in low density lipoproteins induce interleukin-1 beta release from human blood mononuclear cells. J Lipid Res. 1994 Mar;35(3):417-27.

34. Cutler CW, Shinedling EA, Nunn M, Jotwani R, Kim $\mathrm{BO}$, Nares S, et al. Association between periodontitis and hyperlipidemia: cause or effect? J Periodontol. 1999 Dec;70(12):1429-34.
35. Salvi GE, Yalda B, Collins JG, Jones BH, Smith FW, Arnold $\mathrm{RR}$, et al. Inflammatory mediator response as a potential risk marker for periodontal diseases in insulin-dependent diabetes mellitus patients. J Periodontol. 1997 Feb;68(2):12735 .

36. Engebretson SP, Hey-Hadavi J, Ehrhardt FJ, Hsu D, Celenti RS, Grbic JT, et al. Gingival crevicular fluid levels of interleukin-1beta and glycemic control in patients with chronic periodontitis and type 2 diabetes. J Periodontol. 2004 Sep;75(9):1203-8

37. Nishimura F, Takahashi K, Kurihara M, Takashiba S, Murayama Y. Periodontal disease as a complication of diabetes mellitus. Ann Periodontol. 1998 Jul;3(1):20-9.

38. Doxey DL, Nares S, Park B, Trieu C, Cutler CW, Iacopino AM. Diabetes-induced impairment of macrophage cytokine release in a rat model: potential role of serum lipids. Life Sci. 1998;63(13):1127-36

39. Doxey DL, Cutler CW, Iacopino AM. Diabetes prevents periodontitis-induced increases in gingival platelet derived growth factor-B and interleukin 1-beta in a rat model. J Periodontol. 1998 Feb;69(2):113-9.

40. Iacopino AM. Diabetic periodontitis: possible lipid-induced defect in tissue repair through alteration of macrophage phenotype and function. Oral Dis. 1995 Dec;1(4):214-29.

41. He H, Liu R, Desta T, Leone C, Gerstenfeld LC, Graves DT. Diabetes causes decreased osteoclastogenesis, reduced bone formation, and enhanced apoptosis of osteoblastic cells in bacteria stimulated bone loss. Endocrinology. 2004 Jan;145(1):447-52.

42. Wautier JL, Guillausseau PJ. Diabetes, advanced glycation endproducts and vascular disease. Vasc Med. 1998;3(2):1317.

43. Frantzis TG, Reeve CM, Brown AL Jr. The ultrastructure of capillary basement membranes in the attached gingiva of diabetic and nondiabetic patients with periodontal disease. J Periodontol. 1971 Jul;42(7):406-11.

44. Seppala B, Sorsa T, Ainamo J. Morphometric analysis of cellular and vascular changes in gingival connective tissue in long-term insulin-dependent diabetes. J Periodontol. 1997 Dec;68(12):1237-45.

45. Monnier VM, Glomb M, Elgawish A, Sell DR. The mechanism of collagen cross-linking in diabetes: a puzzle nearing resolution. Diabetes. 1996 Jul;45 Suppl 3:S67-72.

46. Schmidt AM, Weidman E, Lalla E, Yan SD, Hori O, Cao R, et al. Advanced glycation endproducts (AGEs) induce oxidant stress in the gingiva: a potential mechanism underlying accelerated periodontal disease associated with diabetes. J Periodontal Res. 1996 Oct;31(7):508-15.

47. Schmidt AM, Yan SD, Wautier JL, Stern D. Activation of receptor for advanced glycation end products: a mechanism for chronic vascular dysfunction in diabetic vasculopathy and atherosclerosis. Circ Res. 1999 Mar 19;84(5):489-97.

48. Schmidt AM, Hori O, Cao R, Yan SD, Brett J, Wautier JL, et al RAGE: a novel cellular receptor for advanced glycation end products. Diabetes. 1996 Jul;45 Suppl 3:S77-80.

49. Katz J, Bhattacharyya I, Farkhondeh-Kish F, Perez FM, Caudle RM, Heft MW. Expression of the receptor of advanced 
glycation end products in gingival tissues of type 2 diabetes patients with chronic periodontal disease: a study utilizing immunohistochemistry and RT-PCR. J Clin Periodontol. 2005 Jan;32(1):40-4.

50. Ross R. Atherosclerosis--an inflammatory disease. N Engl J Med. 1999 Jan 14;340(2):115-26.

51. Lalla E, Lamster IB, Feit M, Huang L, Spessot A, Qu W, et al. Blockade of RAGE suppresses periodontitis-associated bone loss in diabetic mice. J Clin Invest. 2000 Apr;105(8):1117-24.

52. Ryan ME, Ramamurthy NS, Sorsa T, Golub LM. MMPmediated events in diabetes. Ann N Y Acad Sci. 1999 Jun 30;878:311-34.

53. Sorsa $T$, Ingman $T$, Suomalainen $K$, Halinen $S$, Saari $H$, Konttinen YT, et al. Cellular source and tetracyclineinhibition of gingival crevicular fluid collagenase of patients with labile diabetes mellitus. J Clin Periodontol. 1992 Feb;19(2):146-9.

54. McQuibban GA, Gong JH, Tam EM, McCulloch CA, ClarkLewis I, Overall CM. Inflammation dampened by gelatinase A cleavage of monocyte chemoattractant protein-3. Science. 2000 Aug 18;289(5482):1202-6

55. Taylor GW, Burt BA, Becker MP, Genco RJ, Shlossman $\mathrm{M}$, Knowler $\mathrm{WC}$, et al. Severe periodontitis and risk for poor glycemic control in patients with non-insulindependent diabetes mellitus. J Periodontol. 1996 Oct;67(10 Suppl):1085-93.

56. Saremi A, Nelson RG, Tulloch-Reid M, Hanson RL, Sievers ML, Taylor GW, et al. Periodontal disease and mortality in type 2 diabetes. Diabetes Care. 2005 Jan;28(1):27-32.

57. Miller LS, Manwell MA, Newbold D, Reding ME, Rasheed A, Blodgett J, et al. The relationship between reduction in periodontal inflammation and diabetes control: a report of 9 cases. J Periodontol. 1992 Oct;63(10):843-8.

58. Mealey BL, Ocampo GL. Diabetes mellitus and periodontal disease. Periodontol 2000. 2007;44:127-53.

59. Promsudthi A, Pimapansri S, Deerochanawong C, Kanchanavasita W. The effect of periodontal therapy on uncontrolled type 2 diabetes mellitus in older subjects. Oral Dis. 2005 Sep;11(5):293-8.

60. Stewart JE, Wager KA, Friedlander AH, Zadeh HH. The effect of periodontal treatment on glycemic control in patients with type 2 diabetes mellitus. J Clin Periodontol. 2001 Apr;28(4):306-10

61. Kiran M, Arpak N, Unsal E, Erdogan MF. The effect of improved periodontal health on metabolic control in type 2 diabetes mellitus. J Clin Periodontol. 2005 Mar;32(3):266-72.

62. Aldridge JP, Lester V, Watts TL, Collins A, Viberti G, Wilson RF. Single-blind studies of the effects of improved periodontal health on metabolic control in type 1 diabetes mellitus. J Clin Periodontol. 1995 Apr;22(4):271-5.

63. Christgau M, Palitzsch KD, Schmalz G, Kreiner U, Frenzel $\mathrm{S}$. Healing response to non-surgical periodontal therapy in patients with diabetes mellitus: clinical, microbiological, and immunologic results. J Clin Periodontol. 1998 Feb;25(2):11224.

64. Janket SJ, Wightman A, Baird AE, VanDyke TE, Jones JA. Does periodontal treatment improve glycemic control in diabetic patients? A meta-analysis of intervention studies. J Dent Res. 2005 Dec;84(12):1154-9.

65. Hunter W. Oral Sepsis as a Cause of Disease. Br Med J. 1900 Jul 28;2(2065):215-6.

66. WD M. The human mouth as a focus of infection. The Dental Cosmos. 1891 Sep 12;33(9):689-713.

67. Haraszthy VI, Zambon JJ, Trevisan M, Zeid M, Genco RJ. Identification of periodontal pathogens in atheromatous plaques. J Periodontol. 2000 Oct;71(10):1554-60.

68. Noack B, Genco RJ, Trevisan M, Grossi S, Zambon JJ, DeNardin E. Periodontal infections contribute to elevated systemic C-reactive protein level. J Periodontol. 2001 Sep;72(9):1221-7.

69. D'Aiuto F, Parkar M, Andreou G, Suvan J, Brett PM, Ready $\mathrm{D}$, et al. Periodontitis and systemic inflammation: control of the local infection is associated with a reduction in serum inflammatory markers. J Dent Res. 2004 Feb;83(2):156-60.

70. Grossi SG, Genco RJ. Periodontal disease and diabetes mellitus: a two-way relationship. Ann Periodontol. 1998 Jul;3(1):51-61.

71. Prabhu A, Michalowicz BS, Mathur A. Detection of local and systemic cytokines in adult periodontitis. J Periodontol. 1996 May;67(5):515-22.

72. Salvi GE, Brown CE, Fujihashi K, Kiyono H, Smith FW, Beck $\mathrm{JD}$, et al. Inflammatory mediators of the terminal dentition in adult and early onset periodontitis. J Periodontal Res. 1998 May;33(4):212-25.

73. Herzberg MC, Weyer MW. Dental plaque, platelets, and cardiovascular diseases. Ann Periodontol. 1998 Jul;3(1):15160 .

74. Ebersole JL, Cappelli D, Mott G, Kesavalu L, Holt SC, Singer RE. Systemic manifestations of periodontitis in the nonhuman primate. J Periodontal Res. 1999 Oct;34(7):358-62.

75. Neacsu E, Simionescu L, Zimel A, Caragheorgheopol A. The development of a radioimmunoassay system for testosterone (T) and dihydrotestosterone (DHT). Part 3. The preparation of radioiodinated testosterone. Endocrinologie. 1990 JulDec;28(3-4):127-38.

76. Ling PR, Istfan NW, Colon E, Bistrian BR. Differential effects of interleukin-1 receptor antagonist in cytokine- and endotoxin-treated rats. Am J Physiol. 1995 Feb;268(2 Pt 1):E255-61.

77. Kadowaki T, Yamauchi T. Adiponectin and adiponectin receptors. Endocr Rev. 2005 May;26(3):439-51.

78. Grossi SG. Treatment of periodontal disease and control of diabetes: an assessment of the evidence and need for future research. Ann Periodontol. 2001 Dec;6(1):138-45.

79. Agwunobi AO, Reid C, Maycock P, Little RA, Carlson GL. Insulin resistance and substrate utilization in human endotoxemia. J Clin Endocrinol Metab. 2000 Oct;85(10):37708.

80. Vassiliadis S, Dragiotis V, Protopapadakis E, Athanassakis I, Mitlianga P, Konidaris K, et al. The destructive action of IL-1alpha and IL-1beta in IDDM is a multistage process: evidence and confirmation by apoptotic studies, induction of intermediates and electron microscopy. Mediators Inflamm. 1999;8(2):85-91. 
81. Moller DE. Potential role of TNF-alpha in the pathogenesis of insulin resistance and type 2 diabetes. Trends Endocrinol Metab. 2000 Aug;11(6):212-7.

82. Qi C, Pekala PH. Tumor necrosis factor-alpha-induced insulin resistance in adipocytes. Proc Soc Exp Biol Med. 2000 Feb;223(2):128-35.

83. Salvi GE, Carollo-Bittel B, Lang NP. Effects of diabetes mellitus on periodontal and peri-implant conditions: update on associations and risks. J Clin Periodontol. 2008 Sep;35(8 Suppl):398-409.

84. Mealey BL, Rose LF. Diabetes mellitus and inflammatory periodontal diseases. Curr Opin Endocrinol Diabetes Obes. 2008 Apr;15(2):135-41.
85. Engebretson S, Chertog R, Nichols A, Hey-Hadavi J, Celenti R, Grbic J. Plasma levels of tumour necrosis factor-alpha in patients with chronic periodontitis and type 2 diabetes. J Clin Periodontol. 2007 Jan;34(1):18-24.

86. Tervonen $\mathrm{T}$, Knuuttila M, Pohjamo L, Nurkkala $\mathrm{H}$. Immediate response to nonsurgical periodontal treatment in subjects with diabetes mellitus. J Clin Periodontol. 1991 Jan;18(1):65-8.

87. Westfelt E, Rylander H, Blohme G, Jonasson P, Lindhe J. The effect of periodontal therapy in diabetics. Results after 5 years. J Clin Periodontol. 1996 Feb;23(2):92-100. 